\title{
Periodontal Disease with Diabetes or Diabetes Kidney Disease
}

Dr. Amit Kumar Verma

B.D.S. MS.c, DKS Postgraduate Institute \& Research Center, Raipur, Chhattisgarh, India

\begin{abstract}
Periodontitis has been associated with systemic diseases such as diabetes and atherosclerosis, cardiovascular diseases, and even chronic kidney disease (CKD) through low-grade systemic inflammation, although no causality can be drawn. CKD is an increasing problem worldwide, and has adverse effects on oral health. The main risk factors of CKD are diabetes mellitus (DM), hypertension and obesity. Diabetic nephropathy is the main reason for entering dialysis in Finland and cardiovascular diseases (CVD) play a crucial role in mortality among CKD patients. The hypotheses were that diabetic nephropathy patients have worse oral health than other CKD patients, at both predialysis and posttransplantation stages, and that salivary MMP-8 associates with worse oral inflammatory burden. The mortality rate was assumed to be higher among diabetic nephropathy patients. The main expected reason for death was cardiovascular disease.
\end{abstract}

\section{PERIODONTAL DISEASE}

Periodontal disease is the scientific name used to describe gum disease. There are two common forms of periodontal disease. The first is called gingivitis, which is mild inflammation of the gums. The other, more serious, form of gum disease is called periodontitis, in which there is more severe inflammation of the gums, and the bone that holds the teeth in place begins to be gradually destroyed.

\section{RECOGNIZING WHETHER YOU HAVE PERIODONTAL DISEASE}

The most certain way to find out if you have periodontal disease is to visit a dentist. If the dentist suspects that you may have periodontal disease, $\mathrm{x}$ rays of your teeth may be taken to check the health of the bone that holds the teeth in place. Healthy gums are pink and firm, are tightly attached to the teeth, and don't usually bleed when you brush your teeth
1. Gingivitis develops when the teeth are not brushed effectively. Plaque builds up on the teeth, next to the gum, and the bacteria in plaque cause the gums to become inflamed. As a result, the gums look inflamed and swollen and may bleed when you brush your teeth. Gingivitis is totally reversible, and with good oral hygiene the gums can return to normal.

2. Periodontitis, the more serious form of gum disease, results from prolonged (over several years) inflammation of the gums as a result of long-term plaque accumulation. The gum inflammation becomes more and more severe, and the gums start to detach from the tooth. This creates a space between the gum and the tooth called a 'pocket' which is measured by the dentist with a probe.

As the pocket gets deeper, the jaw bone holding the teeth in place is gradually destroyed.

This process is typically painless, and it progresses very slowly. After many years, so much bone may have been destroyed that the tooth starts to become mobile or loose and gums begin to recede, making the teeth look longer than they used to. This may be the first indication to some patients that there is a problem.

\section{PERIODONTAL DISEASE WITH DIABETES}

In people with diabetes there is an increased incidence of periodontal disease.

We still don't know the precise reasons why people with diabetes are more likely to suffer from periodontal disease, and this is an ongoing area of research. There are probably several factors which are important, including:

The immune system may not function properly in people with diabetes, thereby increasing the risk of periodontal disease 
$>$ Excess lipid tissue (body fat) in obese people with diabetes may produce chemicals which make the gums more likely to become inflamed

$>$ Damage to capillaries (the small delicate blood vessels) in the gums may reduce the blood supply to the gums, thereby limiting the actions of defense cells

$>$ Wound healing is impaired in diabetes, and therefore, healing in the gums is also reduce

The key thing to remember is that glycemic control (blood sugar level) seems to be very important in determining susceptibility to periodontal disease. Research suggests that individuals with good diabetes control A1C $<7$ have a reduced risk of periodontal disease compared to individuals with an $\mathrm{A} 1 \mathrm{C}>8.5$.

\section{Diabetes}

Damages

Bodies Cells

When you have diabetes, you don't have enough insulin in your blood (an organ in your body called the pancreas makes insulin). Insulin controls the movement of blood sugar into the cells of the body.

For body cells to continue growing and working, they need energy (blood sugar is the energy source your body cells feed on). When there is no insulin, body cells cannot get the blood sugar they need. This leads to the blood sugar accumulating in the blood (excess blood sugar).

Have you ever watched soil soak up water? Just like that, excess blood sugar in the blood will get water out of your bodies cells, shrinking them and making them unhealthy. If this continues for a long period, your cells will continue to damage and eventually die.

Lack of insulin affects other cells, such as nerve cells, in a different way. Nerve cells make up your brain and body nerves, which carry signals from your brain to your body parts.

Nerve cells will allow blood sugar to get into them without the help of insulin. Without insulin, the blood sugar will not feed the cells. The sugar will accumulate in the cells and damage them. Damaged nerve cells cause numbness and tingling in the feet and hands.

Excess blood sugar in the blood also damages the cells in blood vessels. This damage reduces blood circulation. This is why people with diabetes lose their legs, kidney functions and eye sight.

Glucose is present in your saliva - the fluid in your mouth that makes it wet. When diabetes is not controlled, high glucose levels in your saliva help harmful bacteria grow. These bacteria combine with food to form a soft, sticky film called plaque. Plaque also comes from eating foods that contain sugars or starches. Some types of plaque cause tooth decay or cavities. Other types of plaque cause gum disease and bad breath.

Gum disease can be more severe and take longer to heal if you have diabetes. In turn, having gum disease can make your blood glucose hard to control.

\section{high glucose levels $=\boldsymbol{O}$ plaque}

\begin{tabular}{|c|c|c|c|}
\hline Problem & What It Is & Symptoms & Treatment \\
\hline gingivitis & $\begin{array}{l}\text { unhealthy or inflamed } \\
\text { gums }\end{array}$ & $\begin{array}{l}>\text { red, swollen, and bleeding } \\
\text { gums }\end{array}$ & $\begin{array}{l}>\text { daily brushing and flossing } \\
>\text { regular cleanings at the dentist }\end{array}$ \\
\hline periodontitis & $\begin{array}{l}\text { gum disease, which can } \\
\text { change from mild to } \\
\text { severe }\end{array}$ & $\begin{array}{l}>\text { red, swollen, and bleeding } \\
\text { gums } \\
>\text { gums that have pulled } \\
\text { away from the teeth } \\
>\text { long-lasting infection } \\
\text { between the teeth and } \\
\text { gums } \\
>\text { bad breath that won't go } \\
\text { away } \\
>\text { permanent teeth that are } \\
\text { loose or moving away }\end{array}$ & $\begin{array}{l}>\text { deep cleaning at your dentist } \\
>\text { medicine that your dentist } \\
\text { prescribes } \\
>\text { gum surgery in severe cases }\end{array}$ \\
\hline
\end{tabular}




\begin{tabular}{|c|c|c|c|}
\hline & & $\begin{array}{l}\text { from one another } \\
\text { changes in the way your } \\
\text { teeth fit together when you } \\
\text { bite } \\
>\text { sometimes pus between } \\
\text { the teeth and gums } \\
\text { changes in the fit of } \\
\text { dentures, which are teeth } \\
\text { you can remove }\end{array}$ & \\
\hline $\begin{array}{l}\text { thrush, } \\
\text { called } \\
\text { candidiasis }\end{array}$ & $\begin{array}{l}\text { the growth of a } \\
\text { naturally occurring } \\
\text { fungus that the body is } \\
\text { unable to control }\end{array}$ & $\begin{array}{l}\text { sore, white-or sometimes } \\
\text { red-patches on your } \\
\text { gums, tongue, cheeks, or } \\
\text { the roof of your mouth } \\
\text { patches that have turned } \\
\text { into open sores }\end{array}$ & $\begin{array}{l}>\text { medicine that your doctor or } \\
\text { dentist prescribes to kill the } \\
\text { fungus } \\
>\text { cleaning dentures } \\
>\text { removing dentures for part of } \\
\text { the day or night, and soaking } \\
\text { them in medicine that your } \\
\text { doctor or dentist prescribes }\end{array}$ \\
\hline $\begin{array}{l}\text { dry mouth, } \\
\text { called } \\
\text { xerostomia }\end{array}$ & $\begin{array}{l}\text { a lack of saliva in your } \\
\text { mouth, which raises } \\
\text { your risk for tooth } \\
\text { decay and gum disease }\end{array}$ & $\begin{array}{l}\text { dry feeling in your mouth, } \\
\text { often or all of the time } \\
>\text { dry, rough tongue } \\
>\text { pain in the mouth } \\
\text { cracked lips } \\
>\text { mouth sores or infection } \\
>\text { problems chewing, eating, } \\
\text { swallowing, or talking } \\
\text { Resend in Scientilc } \\
\text { Development }\end{array}$ & $\begin{array}{l}\text { taking medicine to keep your } \\
\text { mouth wet that your doctor or } \\
\text { dentist prescribes } \\
\text { rinsing with a fluoride mouth } \\
\text { rinse to prevent cavities } \\
\text { using sugarless gum or mints } \\
\text { to increase saliva flow } \\
\text { taking frequent sips of water } \\
\text { avoiding tobacco, caffeine, } \\
\text { and alcoholic beverages } \\
\text { using a humidifier, a device } \\
\text { that raises the level of } \\
\text { moisture in your home, at } \\
\text { night } \\
\text { avoiding spicy or salty foods } \\
\text { that may cause pain in a dry } \\
\text { mouth }\end{array}$ \\
\hline oral burning & $\begin{array}{l}\text { a burning sensation } \\
\text { inside the mouth } \\
\text { caused by uncontrolled } \\
\text { blood glucose levels }\end{array}$ & $\begin{array}{l}>\text { burning feeling in the } \\
\text { mouth } \\
>\text { dry mouth } \\
>\text { bitter taste } \\
>\text { symptoms may worsen } \\
\text { throughout the day }\end{array}$ & $\begin{array}{l}>\text { seeing your doctor, who may } \\
\text { change your diabetes } \\
\text { medicine } \\
\text { once your blood glucose is } \\
\text { under control, the oral burning } \\
\text { will go away }\end{array}$ \\
\hline
\end{tabular}

The relationship between diabetes and gum disease is well documented, and several ways that diabetes impacts gum's health are described:

$>$ Increased infection risk. Diabetes is known to have a negative impact on the body's immune system. The reduced efficiency of white blood cells to fight infections increases the risk of developing gum disease which is a bacterial infection of the soft and hard tissues of the mouth.

$>$ Impaired healing. One of the main characteristics of diabetes is that the body has reduced healing ability. Any wound is much more difficult to heal in diabetics. Damage caused to soft tissues by gum disease is much more severe in patients with diabetes due to the impaired healing ability. When a healthy patient might experience a mild gingivitis, under the same conditions the diabetic patient may suffer from severe periodontitis.

> Increased sugar levels. Many of the bacteria that cause periodontal disease use sugar as their main nutrient. Poor diabetic control and increased sugar 
levels in the blood can actually enhance the growth of the bacteria that cause oral infections.

$>$ Structural cell damage. Poorly controlled insulin-dependent diabetics have destructive changes in the blood vessels and the cells of supporting tissues such as the gums, making patients more susceptible to gum problems.

> Blood Vessel Changes. Thickening of blood vessels is a complication of diabetes that may increase risk for gum disease. Blood vessels deliver oxygen and nourishment to body tissues, including the mouth, and carry away the tissues' waste products. Diabetes causes blood vessels to thicken, which slows the flow of nutrients and the removal of harmful wastes. This can weaken the resistance of gum and bone tissue to infection.

$>$ Bacteria. Many kinds of bacteria (germs) thrive on sugars, including glucose -- the sugar linked to diabetes. When diabetes is poorly controlled, high glucose levels in mouth fluids may help germs grow and set the stage for gum disease.

$>$ Xerostomia is a subjective symptom of dry mouth which does not always go hand in hand with physical signs of salivary gland hypofunction. Hyposalivation, as an objective term, is defined when unstimulated salivary flow rate is $\mathrm{c}<$ $0.1 \mathrm{ml} / \mathrm{min}$, and stimulated salivary flow rate is $<$ $0.7 \mathrm{ml} / \mathrm{min}$. Medication such as antihypertensive drugs, antidepressants, and antihistamines antidiabetes

Diabetes may disturb salivary gland function and result in reduced salivary flow. Hyposalivation predisposes to many disorders such as dysphagia (difficulty in swallowing), dysgeusia (altered taste sensation), dysphonia, pain, burning mouth, and oral infectious diseases such as caries and periodontal diseases, or even life-threatening bacterial and yeast infections and aspiration pneumonia.

About $90 \%$ of saliva is produced by the major salivary glands: the parotid, submandibular and sublingual glands. Saliva is mainly composed of water (90\%) with electrolytes and proteins such as immunoglobulins; and antifungal, antibacterial and digestive enzymes. Normally daily saliva volume varies from 0.5 to 1 liters per day. Saliva is indeed an important lubricant of oral and upper gastrointestinal mucosa, and has antimicrobial, buffering and demineralization properties.
The main risk factors of chronic kidney failure are diabetes, hypertension, and obesity in developed as well as many developing countries, Other etiological causes of CKD are systemic autoimmune diseases, polycystic kidney disease, obstructive uropathy, chronic pyelonephritis, and other low-grade systemic inflammatory diseases, such as periodontitis Acute kidney injury, on the other hand, is often associated with bacterial infection, sepsis or ischemiareperfusion injury.

Diabetes as an inflammation-associated disease may contribute to renal inflammation and further to the development of diabetic nephropathy. Renal inflammation can result from metabolic and renal hemodynamic routes caused by hyperglycemia, reactive oxygen species (ROS), and AGEs, or glomerular hypertension and endothelial dysfunction.

Hyperglycemia leads to an abnormal hyperinflammatory response to periodontopathogens in the periodontium . Cell surface receptors (RAGEs) for advanced glycation end products (AGEs) in gingiva are expressed, and RAGE-AGE interaction leads to immune dysfunction, exaggerated inflammatory response and oxidative stress, thus further accelerating AGE and pro-inflammatory cytokine formation, the destruction of tooth supported structures, and impaired wound healing.

So far, hyperglycemia has shown no relationship with periodontal microbiota. However, diabetic patients with periodontitis seem to have elevated numbers of pro-inflammatory mediators such as IL-1, IL-6, and increased RANKL/OPG ratios compared with systemically healthy controls with periodontitis. This partly explains bone resorption in periodontitis. However, it is noteworthy that diabetic patients with well-controlled blood sugar levels are not at an increased risk of periodontitis.

Untreated periodontitis may increase systemic proinflammatory mediators, causing insulin resistance.

\section{Chronic kidney disease // DKD}

Inflammation and atherosclerosis, both related to periodontitis, are shown to predispose patients to CKD. Rahmati and co-workers were the first to show an association between serum IgG to periodontal bacteria (P.gingivalis) and elevated level of C-reactive protein in hemodialysis patients. A crosssectional study by Kshirsagar and co-workers showed that a 
reduction in GFR was connected to periodontal disease. Chambrone and co-workers in Chronic kidney disease Inflammation and atherosclerosis, both related to periodontitis, are shown to predispose patients to CKD. Rahmati and co-workers were the first to show an association between serum IgG to periodontal bacteria (P.gingivalis) and elevated level of C-reactive protein in hemodialysis patients. A crosssectional study by Kshirsagar and co-workers showed that a reduction in GFR was connected to periodontal disease.

\section{Oral manifestation of chronic kidney disease}

CKD may be accompanied by other systemic diseases with oral mucosal manifestations. Aphthous ulcers of oral mucosa may be associated with Behcets disease, which is linked to rapidly progressive glomerulonephritis; or with systemic lupus erythematosus (SLE), which is characterized by lupus nephritis. Strawberry gingivitis may be the first manifestation of systemic vasculitis, Wegeners granulomatosis. Macroglossia may be due to deposits of amyloids. CKD patients may also present many oral changes due to medication or the disease itself affecting teeth, oral mucosa, periodontium, and the salivary glands. Reported changes in teeth include pulp narrowing, enamel hypoplasia, dental caries, and periodontitis. Hyposalivation due to diabetes or medication is harmful, as it increases microbial colonization, thus enhancing oral diseases.

The different stages of CKD, namely predialysis-, dialysis and the post-transplantation stage may manifest in different ways in oral health. Different CKD diagnoses, such as diabetic nephropathy, have also shown characteristic oral health manifestations.

\section{Predialysis stage}

Uremic patients have shown a worse DMFT index and more periodontal loss of attachment and periapical lesions than sex- and age-matched controls. At the predialysis stage, protein intake is restricted, while Predialysis stage Uremic patients have shown a worse DMFT index and more periodontal loss of attachment and periapical lesions than sex- and agematched controls. At the predialysis stage, protein intake is restricted, while sufficient energy is secured by intake of carbohydrates. This may detrimentally affect dental and oral health. Diabetic patients should be informed of their greater risk of periodontitis, the adverse effects of poor glycemic control on periodontitis, and the increased risk of systemic problems such as cardiovascular complications or the progression of CKD.

\section{Dialysis}

Oral health often deteriorates in patients receiving hemodialysis therapy. As hemodialysis treatment is time consuming, usually requiring four to six hours three times per week, treatment may be stressful for the patient. This may lead to having no strength to maintain proper oral health. Moreover, dialysis is regarded as an immunosuppressive state which further affects oral health.

Symptoms such as oral malodor (ammonia-like smell, typical for uremic patients), dry mouth (xerostomia), and taste changes (metallic taste) have been reported in dialysis patients. Medication such as antihypertensive drugs and diuretics may predispose to poor oral health through hyposalivation. This may also affect denture retention and cause difficulties in speaking and eating. The reduction of fluid intake may cause general weakening and a reduced salivary flow rate. These changes may lead to problems in mucosa and predispose to oral fungal and viral infections, as well as coated tongue, sialdenitis, oral ulceration, enamel hypoplasia, increased dental calculus formation, and caries development. In contrast, some studies have shown a prevalence of reduced caries in ESRD, perhaps due to the protective, neutralizing role of urea in saliva and plaque.

In oral health care, attention should be paid to prolonged bleeding time after tooth extraction or periodontal treatment due to heparin administration in hemodialysis, drugs used for treatment (GFR is decreased), and the need for antibiotic prophylaxis (vascular access sites protection)

\section{Post-transplantation stage}

Transplant patients may have oral manifestations such as gingival hyperplasia due to immunosuppressants (cyclosporine) and antihypertensive drugs (calcium channel blockers). Cyclosporine-induced gingival hyperplasia ranges from $22 \%$ to $58 \%$, and is more prevalent among young patients and patients with increased dental plaque accumulation or an increased drug dosage.

Transplant patients are also prone to virus infections, ulcers and oral malignancies. Fungal infections are found in $2030 \%$ of transplant patients, and may 
manifest as angular cheilitis, pseudomembranous or erythematous ulcerations. In their two-year follow-up investigation, Bots and co-workers found that xerostomia and thirst decreased, and unstimulated salivary flow rate increased after kidney transplantation compared to dialysis state.

Oral health care professionals should pay attention to the fact that a patient with a transplanted organ needs immunosuppressive drugs for the rest of their life. These drugs may predispose patients to oral inflammations and fungal and viral infections as well as malignancies or gingival overgrowth induced by cyclosporine and calcium channel blockers. Therefore, oral examination of transplant patients calls for special attention, preferably in a specialist clinic . Antibiotic prophylaxis is mandatory when treating transplant patients.

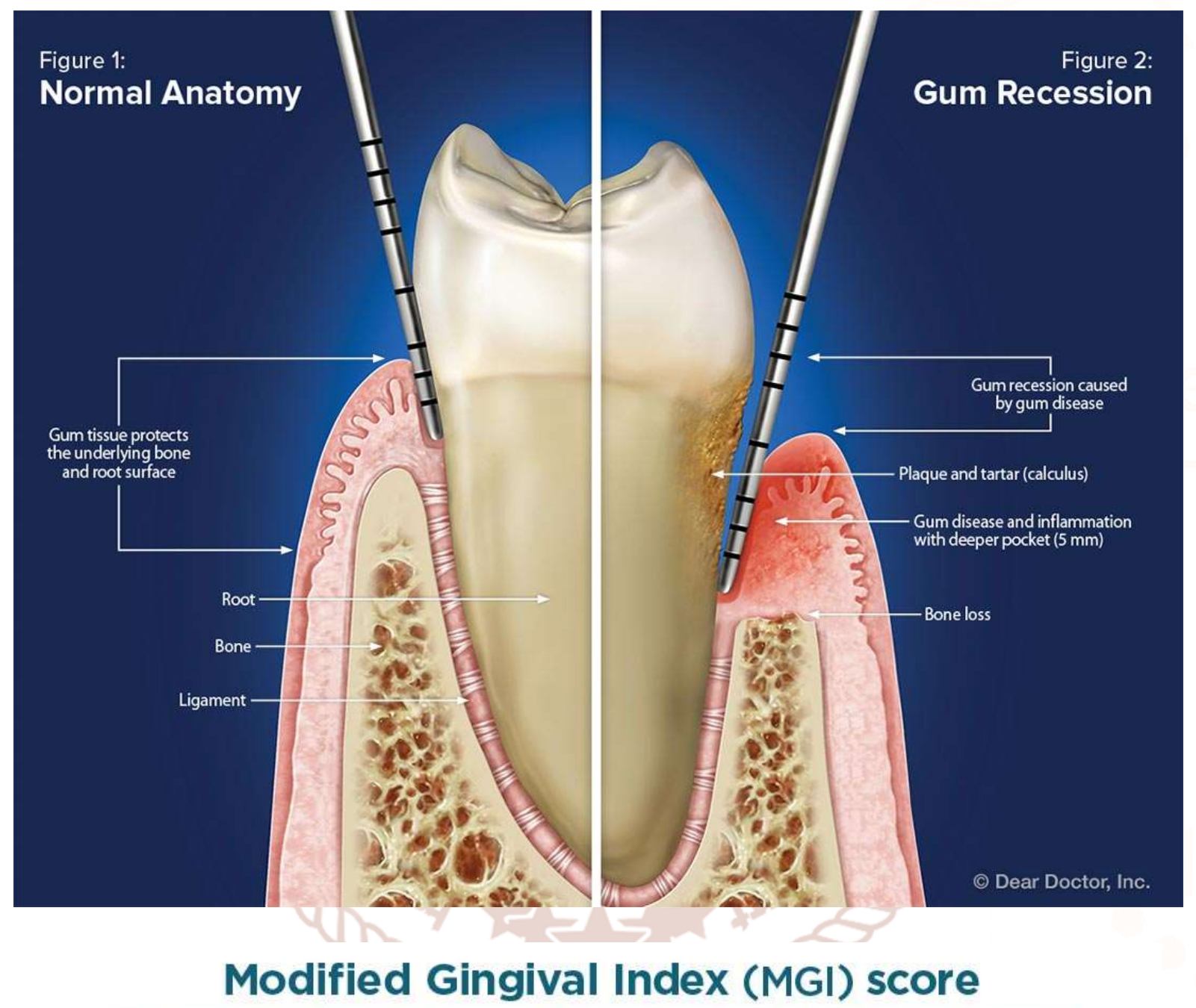

Healthy sites were those with mild (1) to no (0) inflammation, based on the MGI scores.

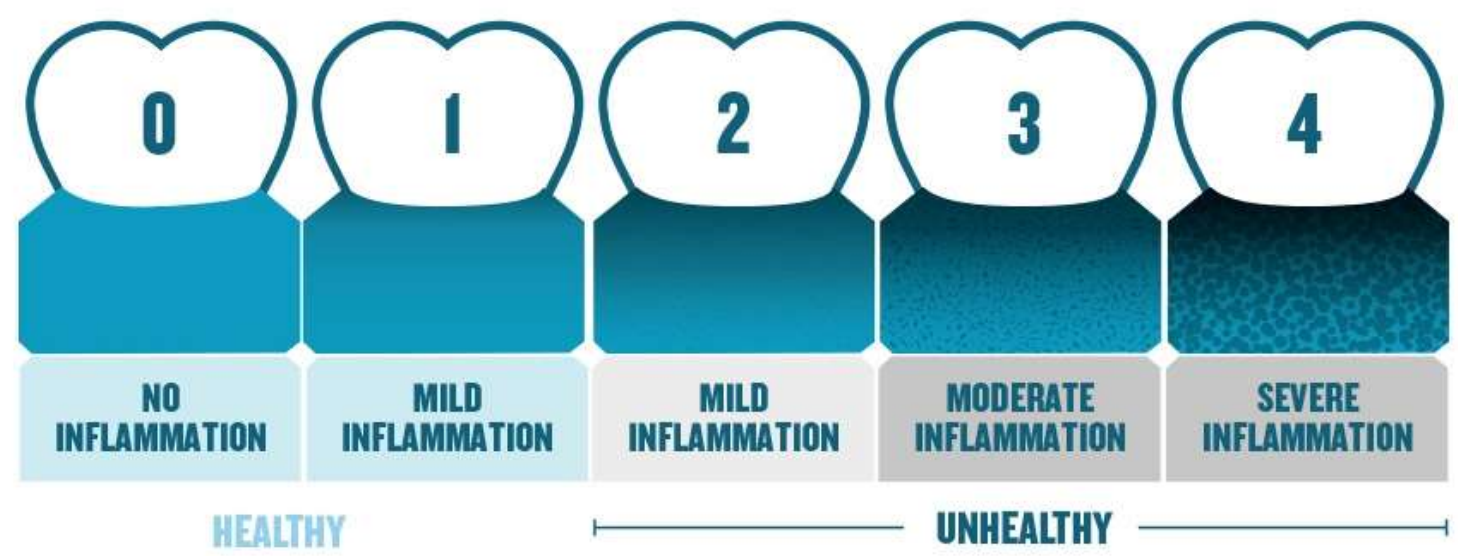



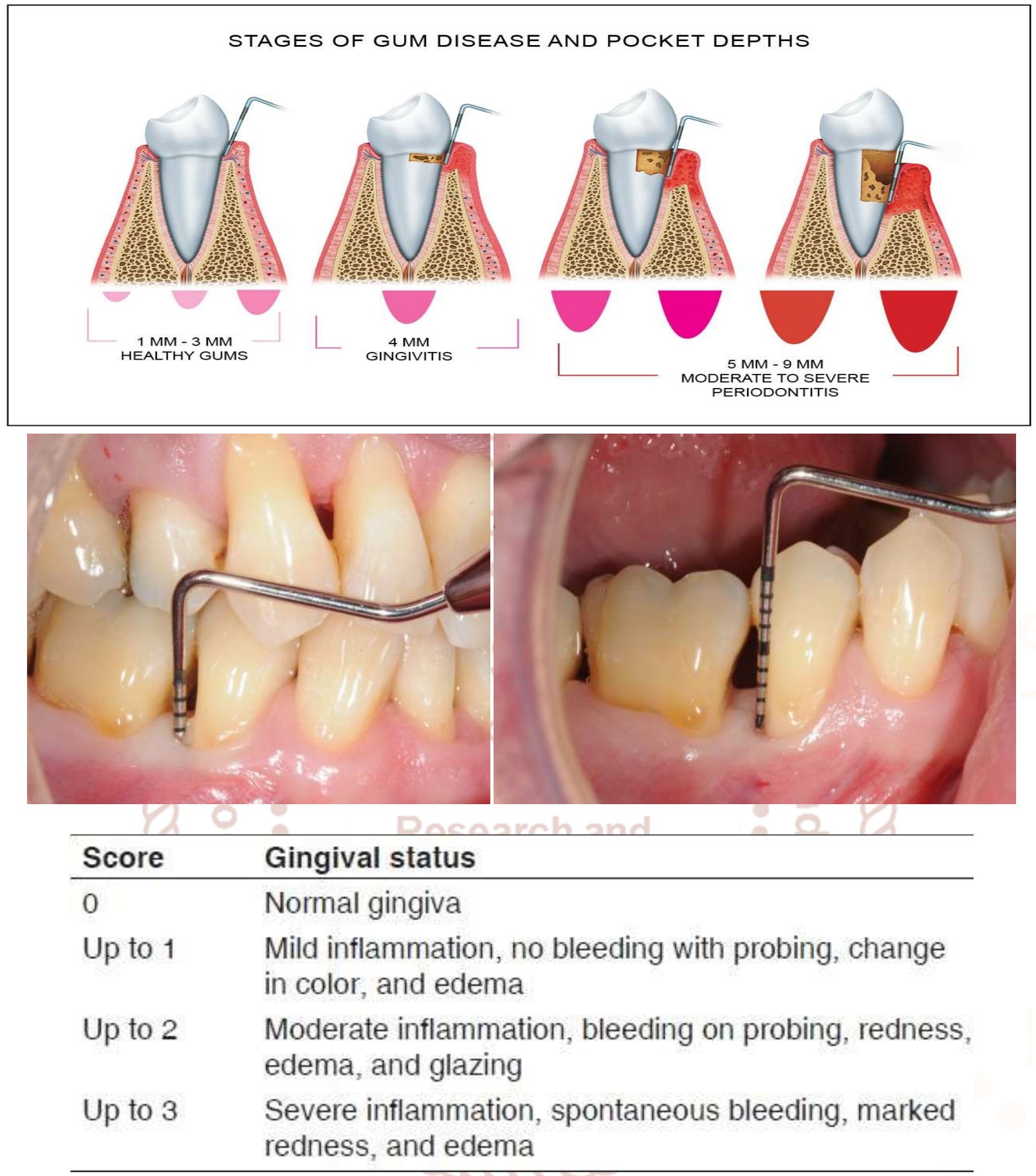

\section{Treatment for periodontal disease}

As with most diseases, prevention is better than a cure. Periodontal disease can generally be prevented by maintaining good oral hygiene (i.e. cleaning your teeth effectively). Brush your teeth twice per day, for approximately 2-3 minutes each time (which is longer than you think when brushing your teeth!). Be sure to brush every surface of the teeth, and particularly the point where the gum meets the tooth. If your teeth are a little overlapping, or there are awkward areas to clean, then use a small (single tufted) brush. The toothbrush should be positioned so the bristles contact the point where the gum meets the tooth at about a 45 degree angle. Use short back and forth strokes of the brush, with gentle pressure. An electric toothbrush brush for most people is as effective as a manual toothbrush. They can also be useful if you have restricted movement. Make sure you clean in between the teeth using floss. If you have problems with gum disease, it is also recommended to use a mouthwash after brushing. Make sure it contains fluoride.

\section{Summing up}

It is very important for all people with diabetes to visit a dentist regularly, so that any gum problems can be detected and treated before they become too severe. 
Your dentist may also clean your teeth for you on a regular basis, or may ask you to see a dental hygienist for cleaning. People with diabetes are more prone to gum disease, especially if their diabetes is poorly controlled. Good oral hygiene and regular dental check-ups are particularly important in people with diabetes.

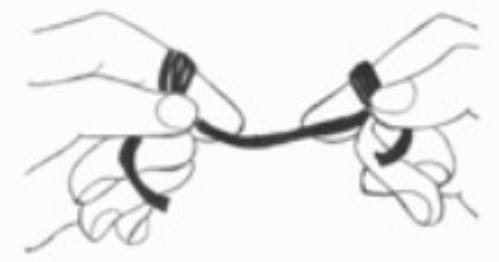

Hold floss

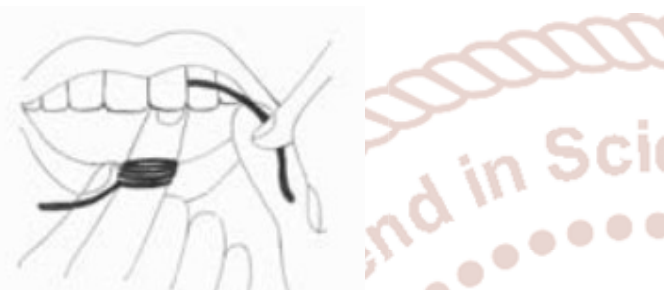

Floss between upper teeth

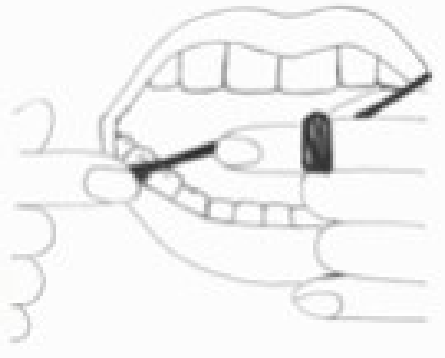

Floss between lower teeth

Key points to remember

$>$ As someone with diabetes you may be more prone to gum problems. See your dentist regularly.

$>$ By keeping good control of your diabetes, and having good blood sugar control, you can reduce the likelihood of gum disease.

$>$ Brush and floss your teeth regularly, being careful to brush every part of the tooth. If this makes the gum bleed, it may be a sign of gum inflammation. If you are concerned about bleeding gums, be sure to visit a dentist.

$>$ Even if you no longer have your own teeth, you should still see a dentist periodically to check the health of your mouth.

$>$ If you have had periodontal disease in the past, it is especially important to continue to see the dentist to make sure the disease does not recur.

$>$ Don't smoke. Smoking makes gum disease worse.

\section{CONCLUSIONS}

In general, the prevalence of periodontal disease was high among CKD patients at the predialysis stage and patients with diabetic nephropathy had poorer periodontal health. As patients at the predialysis stage are prospective dialysis patients and kidney transplant recipients, potential sources of systemic inflammation, such as periodontitis, should be diagnosed and treated on time. Patients with diabetic nephropathy should receive special attention.

Higher salivary MMP-8 concentration was associated with poorer oral health Salivary MMP-8 screening could thus be a beneficial aid for infection foci diagnostics among CKD patients. According to study, fewer teeth significantly associated with risk of death even after adjustment for the known risk factors age and diabetes. Most frequent cause of death among CKD patients was a major adverse cardiovascular event, followed by infection and then malignant disease. Risk of death was higher among patients with diabetes nephropathy. oral health was better at followup than in the predialysis stage during which oral infection treatment was performed. However, diabetic nephropathy patients should be paid special attention, as oral health with an emphasis on periodontitis seems to be poorer among this special group of patients.

\section{All rights reserve}

\section{REFERENCES}

1. Ainamo J, Barmes D, Beagrie G, Cutress $T$, Martin J, Sardo-Infirri J. Development of the World Health Organization (WHO) community periodontal index of treatment needs (CPITN) Int Dent J 1982; 32: 281-291.

2. Akar H, Akar GC, Carrero JJ, Stenvinkel P, Lindholm B. Systemic consequences of poororal health in chronic kidney disease patients Clin J Am Soc Nephrol 2011; 6: 218-226.

3. Al-Nowaiser A, Roberts GJ, Trompeter RS, Wilson M, Lucas VS. Oral health in children with chronic renal failure Pediatr Nephrol 2003; 18: 3945 .

4. Beukers NG, van der Heijden GJ, van Wijk AJ, Loos BG. Periodontitis is an independent risk indicator for atherosclerotic cardiovascular diseases among 60174 participants in a large dental school in the Netherlands $\mathrm{J}$ Epidemiol Community Health 2016; 0: 1-6. 
5. Bostanci N, Ozturk VO, Emingil G, Belibasakis GN. Elevated oral and systemic levels of soluble triggering receptor expressed on myeloid cells-1 (sTREM-1) in periodontitis J Dent Res 2013, 92: 161-165.

6. Bots CP, Brand HS, Poorterman JH, van Amerongen BM, Valentijn-Benz M, Veerman EC, ter Wee PM, Nieuw Amerongen AV. Oral and salivary changes in patients with end stage renal disease (ESRD): a two year follow-up study $\mathrm{Br}$ Dent J 2007; 202: E3.

7. Brinkmann V, Reichard U, Goosmann C, Fauler B, Uhlemann Y, Weiss DS, Weinrauch Y, Zychlinsky A. Neutrophil extracellular traps kill bacteria Science 2004; 303: 1532-1535. Buduneli E, Mäntylä P, Emingil G, Tervahartiala $T$, Pussinen P, Baris N, Akilli A, Atilla G, Sorsa T. Acute myocardial infarction is reflected in salivary matrix metalloproteinase- 8 activation level J Periodontol 2011; 82: 716-725.

8. Chambrone L, Foz AM, Guglielmetti MR, Pannuti CM, Artese HP, Feres M, Romito GA. Periodontitis and chronic kidney disease: a systematic review of the association of diseases and the effect of periodontal treatment on estimated glomerular filtration rate $\mathrm{J}$ Clin Periodontol 2013, 40: 443-456.

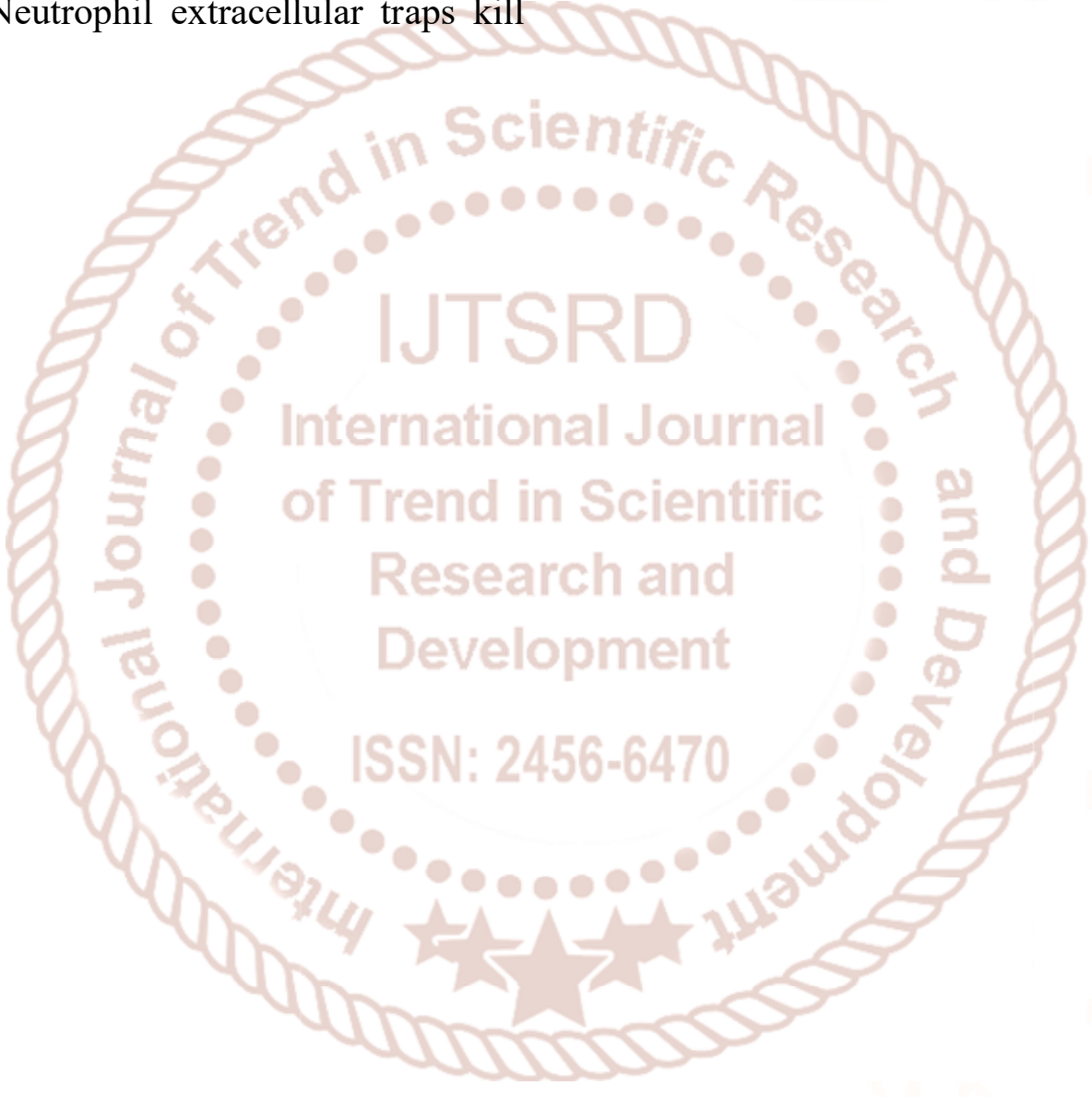

